\title{
Expression of $\beta$-catenin in the developing chick myotome is regulated by
}

\section{myogenic signals}

\author{
Maike Schmidt, Mikiko Tanaka and Andrea Münsterberg* \\ Division of Cell and Developmental Biology, Department of Anatomy and Physiology, Wellcome Trust Biocentre, University of \\ Dundee, Dow Street, Dundee DD1 5EH, UK \\ *Author for correspondence (e-mail: a.e.munsterberg@dundee.ac.uk)
}

Accepted 14 July; published on WWW 7 September 2000

\section{SUMMARY}

The developmental signals that govern cell specification and differentiation in vertebrate somites are well understood. However, little is known about the downstream signalling pathways involved. We have shown previously that a combination of Shh protein and Wnt1 or Wnt3aexpressing fibroblasts is sufficient to activate skeletal muscle-specific gene expression in somite explants. Here, we have examined the molecular mechanisms by which the Wnt-mediated signal acts on myogenic precursor cells. We show that chick frizzled 1 (Fz1), $\beta$-catenin and Lef1 are expressed during somitogenesis. Lef1 and $\beta$-catenin transcripts become restricted to the developing myotome. Furthermore, $\beta$-catenin is expressed prior to the time at which $M y o D$ transcripts can be detected. Expression of $\beta$ -

\section{INTRODUCTION}

Vertebrate somites are segmented mesodermal structures that form on either side of the axial midline tissues, neural tube and notochord during embryogenesis. They are generated sequentially in an anterior to posterior direction. The initially epithelial somite gives rise to three different parts: the dermomyotome, myotome and sclerotome, which contribute to the dermis of the skin, axial skeletal muscle, and cartilage and bone in the adult organism, respectively (Christ and Ordahl, 1995). The tissue interactions and molecular signals important for specification of different cell types within the somite have been well characterised (see Tajbakhsh and Cossu, 1997 for a review).

Skeletal muscle precursor cells originate from the dermomyotome (Christ and Ordahl, 1995). They migrate medially through the dorsomedial lip of the dermomyotome to form the epaxial myotome (Denetclaw et al., 1997). They initiate expression of $M y o D$ and $M y f 5$ as the first sign of commitment to the myogenic lineage. Hypaxial muscle precursors delaminate from the ventral lip of the dermomyotome and migrate to peripheral target sites, including limbs and ventral body wall. It has been demonstrated that myogenic differentiation within the somite is governed by positive and negative signals from surrounding tissues (Borycki et al., 1998; Hirsinger et al., 1997; Johnson et catenin mRNA is regulated by positive and negative signals derived from neural tube, notochord and lateral plate mesoderm. These signals include Bmp4, Shh and Wnt1/Wnt3a itself. In somite explants, $F z 1, \beta$-catenin and Lef1 are expressed prior to activation of myogenesis in response to Shh and Wnt signals. Thus, our data show that a combination of Shh and Wnt1 upregulates expression of Wnt pathway components in developing somites prior to myogenesis. Thus, Wnt1 could act through $\beta$-catenin on cells in the myotome.

Key words: $\beta$-catenin, Wnt signalling, Lef1, Frizzled, Somite, Myogenesis, Chick al., 1994; Marcelle et al., 1997; Münsterberg et al., 1995; Pourquié et al., 1996; Pownall et al., 1996; Reshef et al., 1998; Stern et al., 1995, 1997). Known myogenic signals are derived from both axial midline structures (neural tube, floor plate and notochord; Buffinger and Stockdale, 1994; Münsterberg and Lassar, 1995; Pownall et al., 1996; Stern and Hauschka, 1995) and from lateral plate mesoderm (Pourquié et al., 1995).

Previous work shows that a combination of either Wnt1 or Wnt3a (derived from the developing neural tube) with recombinant Shh protein (derived from floor plate/notochord) is sufficient to activate skeletal muscle-specific genes, including $M y o D$ and $M y f 5$, and the genes for myogenin and myosin heavy chain $(M y h)$ in cultured somites (Münsterberg et al., 1995). We have found that Shh is only transiently required for activation of myogenesis in somite explants and we suggest that Shh acts to sensitise somitic cells for reception of the Wnt signal (Münsterberg et al., 1995). A crucial role of Wnt signalling for skeletal myogenesis has been demonstrated in both avian and mouse embryos (Borello et al., 1999; Hirsinger et al., 1997; Marcelle et al., 1997; Münsterberg et al., 1995; Stern et al., 1995; Tajbakhsh et al., 1998). In addition, it has been shown that Bmp4 expressed in the lateral plate blocks MyoD expression (Pourquié et al., 1996). Therefore, the balance of activating and repressing signals is important for the precise pattern of myogenic differentiation.

Here, we have investigated the role of Wnt pathway 
components in somite differentiation, in particular during myogenesis. Because we have previously identified a transient requirement for Shh in skeletal myogenesis, we also have examined whether Shh regulates components of the Wnt signalling pathway.

The study of Drosophila genetics has helped to identify components of the wingless/Wnt signalling pathway (Arias et al., 1999; Moon et al., 1997). One of the downstream effectors of this pathway is Drosophila armadillo and its vertebrate homologue $\beta$-catenin (Willert and Nusse, 1998). $\beta$-catenin performs at least two functions in the cell: (1) it binds to the cytoplasmic region of cadherins at the plasma membrane, where it plays an important role for changes in cell adhesion and cell shape; (2) free cytoplasmic $\beta$-catenin protein has the ability to interact with HMG box transcription factors and thereby promotes transcriptional activation of target genes in the nucleus.

This latter function of $\beta$-catenin is highly regulated by Wnt. In the absence of Wnt, $\beta$-catenin becomes phosphorylated and degraded via the proteasome pathway. Binding of Wnt to its putative receptor, frizzled $(\mathrm{Fz})$, results in inactivation of Gsk-3 $\beta$ kinase activity and accumulation of $\beta$-catenin in the cell. $\beta$-catenin then interacts with HMG box transcription factors of the Lef/TCF family to activate transcription in the nucleus. Because Lef/TCF can also interact with transcriptional repressors (Cavallo et al., 1998; Roose et al., 1998), it is possible that $\beta$-catenin has to compete for binding to Lef/TCF.

We have investigated the role of chick Fz1, $\beta$-catenin and Lef1 in somite differentiation and myogenesis. $F z 1$ is expressed in the dermatome and myotome, while $\beta$-catenin and Lef1 are expressed exclusively in the myotome. $\beta$-catenin and Lef1 are not only highly expressed specifically in the dorsomedial lip of the myotome, but in addition their transcripts are detected prior to $M y o D$, both in vivo and in vitro. Surgical experiments show that $\beta$-catenin expression depends on signals derived from axial midline tissues, neural tube and notochord, while it is inhibited by signals from lateral plate mesoderm.

Furthermore, Wnt1 and Wnt3a can substitute for the presence of the neural tube and can induce $\beta$-catenin expression after neural tube ablation, while Wnt5a and Wnt7a are unable to do so. In addition, Wnt1 and Wnt3a can act together with Shh to induce $\beta$-catenin expression after removal of axial midline tissues. Furthermore, inhibition of Bmp4 is sufficient for ectopic $\beta$-catenin expression in the lateral somite.

\section{MATERIALS AND METHODS}

\section{Primers, probes, in situ hybridisation, sections and photography}

Chick $F z 1, \quad \beta$-catenin and Lefl cDNAs were amplified from embryonic cDNA using primers hybridising to the published sequence: $F z 1$, accession number AF031830 (Kengaku et al., 1997), 5'-GGGCGGCACCGACTGAGCAT-3', 5'-GAGAACAAAACCCCCAAGTCTGTCC-3'; chick $\beta$-catenin, accession number U82964 (Lu et al., 1997), 5'-TGGGAGCACAGCAAGGAACA-3', 5'-AGCAACTCTACAGGCCAATCAATG-3'; chick Lef1, accession number AF064462 (Kengaku et al., 1998), 5'-CTGCGCCACCGACGAGATGAT-3'， 5'-TGGGGATGGGTGGCGACAGAG-3'. The PCR products were subcloned into pGEM-T-Easy (Promega), and used to derive probes for in situ hybridisation. Antisense DIG-labelled RNA probes were generated according to manufacturers protocol (Promega). In situ hybridisation was performed as described by Henrique et al. (1995). The following probes were used in this study: (1) a $400 \mathrm{bp}$ probe representing the $3^{\prime}$ end of the $F z 1$ coding sequence; (2) a $400 \mathrm{bp}$ probe representing the $3^{\prime}$ end of the $\beta$-catenin coding sequence; (3) a 356 bp probe representing the $5^{\prime}$ end of LefI coding sequence, not including the highly conserved HMG-box; and (4) a $1500 \mathrm{bp}$ probe representing the complete coding sequence of chicken $M y o D$ and $5^{\prime}$ and $3^{\prime}$ untranslated regions, obtained from Bruce Patterson. Stained embryos were embedded in gelatine, as described in Stern (1993), frozen and sectioned at 20-40 $\mu \mathrm{m}$ with a Leica CM1900 Cryostat. Whole-mount embryos were photographed with a RS Photometrics coolsnap digital camera on a Leica MZ8 stereo dissection scope, sections were photographed with a MTI digital camera on a Leica MZ8 microscope and all photographic data was collected with Openlab software (Improvision, Coventry, UK).

\section{Chick embryos and in ovo manipulations}

Fertile chicken White Leghorn eggs were obtain from Needle farm, Hartfordshire, UK, and incubated at $37.5^{\circ} \mathrm{C}$ in a humidified incubator (Ehret) until the desired Hamburger-Hamilton (HH) stage was reached. Pellets of parental or Wnt-expressing RatB1a fibroblasts (Münsterberg et al., 1995), noggin-expressing CHO-cells (Lamb et al., 1993) and Shh-expressing chicken embryonic fibroblasts (CEF) cells were generated by growing the cells in suspension on bacterial dishes. The resulting cell aggregates were implanted into HH 10 embryos. Mixed cell pellets were generated by combining trypsinised cells 1:1 after thorough washes with medium. Cells were collected by centrifugation for 2 minutes at $2000 \mathrm{rpm}$ in a $1.5 \mathrm{ml}$ tube, followed by a 30 minute incubation at $37^{\circ} \mathrm{C}$ and another centrifugation for 2 minutes at $2000 \mathrm{rpm}$. The resulting cell pellet was transferred into a petri dish and cut to a suitable size for implantation using a scalpel. In ovo surgical experiments were performed as described in (Pourquié et al., 1995). Embyros were fixed in $4 \%$ paraformaldehyde and processed for in situ hybridisation 16 to 18 hours after the operation.

\section{Explant cultures and RT-PCR}

Embryonic tissues were isolated and cultured as described in (Münsterberg and Lassar, 1995). Co-culture of paraxial mesoderm explants with RatB1a fibroblasts was performed essentially as described in (Münsterberg et al., 1995), except that cell aggregates were generated by growing cells on bacterial dishes for 2 days. Shh was added at a concentration of $200 \mathrm{ng} / \mathrm{ml}$ and Bmp4 was added at a concentration of $100 \mathrm{ng} / \mathrm{ml}$. RT-PCR was performed as has been previously described (Münsterberg et al., 1995; Münsterberg and Lassar, 1995). After production of cDNA using MMTV-Reverse transcriptase (Promega), individual PCR reactions were performed with appropriate primer pairs for different genes. The radiolabelled PCR products were visualised by polyacrylamide gel electrophoresis and autoradiography. Each PCR cycle was $93^{\circ} \mathrm{C}$ for 30 seconds, $60^{\circ} \mathrm{C}$ for 40 seconds, and $72^{\circ} \mathrm{C}$ for 1 minute. Paxl and Shh were amplified in the presence of 5\% formamide with an annealing temperature of $50^{\circ} \mathrm{C}$. Amplification was within the linear range, between 27 to 30 cycles. The primers used for PCR amplification were as described in (Münsterberg et al., 1995; Münsterberg and Lassar, 1995) and as follows: Lef1, 5'-CTGCGCCACCGACGAGATGAT-3' and 5'-TGGGGATGGGTGGCGACAGAG-3', amplifying from position -16 to +340 (356 bp); Fz1, 5'-CTAGCGGCCGGCATGAAGTGG-3', 5'TGGGGCAGGGGATGGCATAG-3', +1343 to +1805 (463 bp); $\beta$ catenin, 5' - TGCGCTCCGTCACCTCACC-3', 5' -ATGCGCACACCCTCCACAAACT-3', +1506 to +1805 (300 bp). The specificity of the amplification was verified for these primers by restriction mapping of the PCR products and/or sequencing. 


\section{RESULTS}

\section{Expression of chick Fz1, $\beta$-catenin and Lef1 during somitogenesis}

To investigate further the role of Wnt for skeletal muscle specification we examined the developmental expression of a putative Wnt receptor, $F z l$, and the intracellular effectors, $\beta$ catenin and Lefl in chick embryos. Whole-mount in situ hybridisation was performed on embryos from stages $\mathrm{HH} 7$ to 22. This analysis demonstrates a dynamic expression of chick $F z 1, \beta$-catenin and Lefl transcripts in paraxial mesoderm during somitogenesis (Fig. 1A,E,I; HH 14). Analysis of whole-mount embryos showed that all three genes are expressed to varying levels in presegmented mesoderm. Fzl is expressed weakly in this tissue and becomes upregulated slightly in the region of the next prospective somite (Fig. 1A). In contrast $\beta$-catenin is expressed moderately (Figs 1E and 2A) and Lefl (Fig. 1I) is expressed strongly in presegmented mesoderm. The pattern of $\beta$-catenin and Lef1 expression becomes more restricted to medial somites as they differentiate. The relative levels of expression of $F z l, \beta$-catenin and Lefl in presegmented mesoderm is also apparent from RT-PCR analysis (see below, Fig. 3, lane 1).

Transverse sections at different anterior to posterior levels demonstrate that $F z l$ is expressed at low levels throughout epithelial somites (Fig. 1D). Chick $F z l$ expression then becomes restricted to the dermamyotome (Fig. 1C) and in more mature somites it is expressed in dermatome and myotome (Fig. 1B).

For $\beta$-catenin we observed a very striking pattern of expression during somite development. Sections revealed that $\beta$-catenin was expressed evenly throughout the epithelial somite (Fig. 1H). As the myotome forms at the dorsomedial edge of the somite, $\beta$-catenin becomes highly expressed and restricted to this region (Fig. 1G). Subsequently, $\beta$ catenin expression is maintained at high levels specifically in the myotome as it expands beneath the dermatome (Fig. 1F).

Lef1 is expressed at high levels in the anterior half of pre-segmented mesoderm (somites -I to -VI, Fig. 1I). It is expressed throughout epithelial somites at lower levels (Fig. 1I,L). Expression is maintained during somite differentiation and transcripts become localised to the myotome as the somite differentiates (Fig. 1K,J).

Fig. 1. Dynamic expression of $F z 1, \beta$-catenin and Lef1 during somitogenesis. In situ hybridisations performed on chick embryos of stage $\mathrm{HH} 14$ show expression of $F z 1$ (A-D), $\beta$-catenin (E-H) and Lefl (I-L). Shown are wholemount embryos (A,E,I) and sections representing different stages of somite differentiation within the same embryo. Horizontal black lines indicate the axial level at which sections were taken. The most posterior sections are shown in the bottom panels (D,H,L). Epithelial somites (somite II) from posterior regions of the axis are shown in $(\mathrm{D}, \mathrm{H}, \mathrm{L})$, somites XII are shown in $(\mathrm{C}, \mathrm{G}, \mathrm{K})$ and somites XVIII shown in $(\mathrm{B}, \mathrm{F}, \mathrm{J})$.

\section{Expression of $\beta$-catenin in developing somites precedes that of $M y o D$ in vivo}

Next, we performed a side-by-side comparison of $\beta$-catenin with $M y o D$ expression in staged embryos. $\beta$-catenin is expressed in all epithelial somites, starting with the first formed somite at stage $\mathrm{HH} 7$, when $M y o D$ transcripts cannot be detected (data not shown). At stage HH 12 (Fig. 2A-H) $\beta$ catenin is expressed in all somites while MyoD expression is turned on only in more-anterior, more-differentiated somites (compare Fig. 2A and E). Both whole-mount embryos and sections show that $\beta$-catenin expression becomes restricted to medial somite regions prior to any detectable expression of $M y o D$ (compare Fig. 2D and $\mathrm{H}$ ). As somite differentiation proceeds, $\beta$-catenin and $M y o D$ are expressed in an overlapping pattern (Fig. 2C,G). Both genes are co-expressed in the dorsomedial lip of the early myotome (Fig. 2B,F) and the expanding myotome of more mature somites (Fig. 2I,J,L,M; $\mathrm{HH} 14$ embryo). $\beta$-catenin expression begins to fade in myotomes of anterior somites of HH 14 embryos (Fig. 2I) and
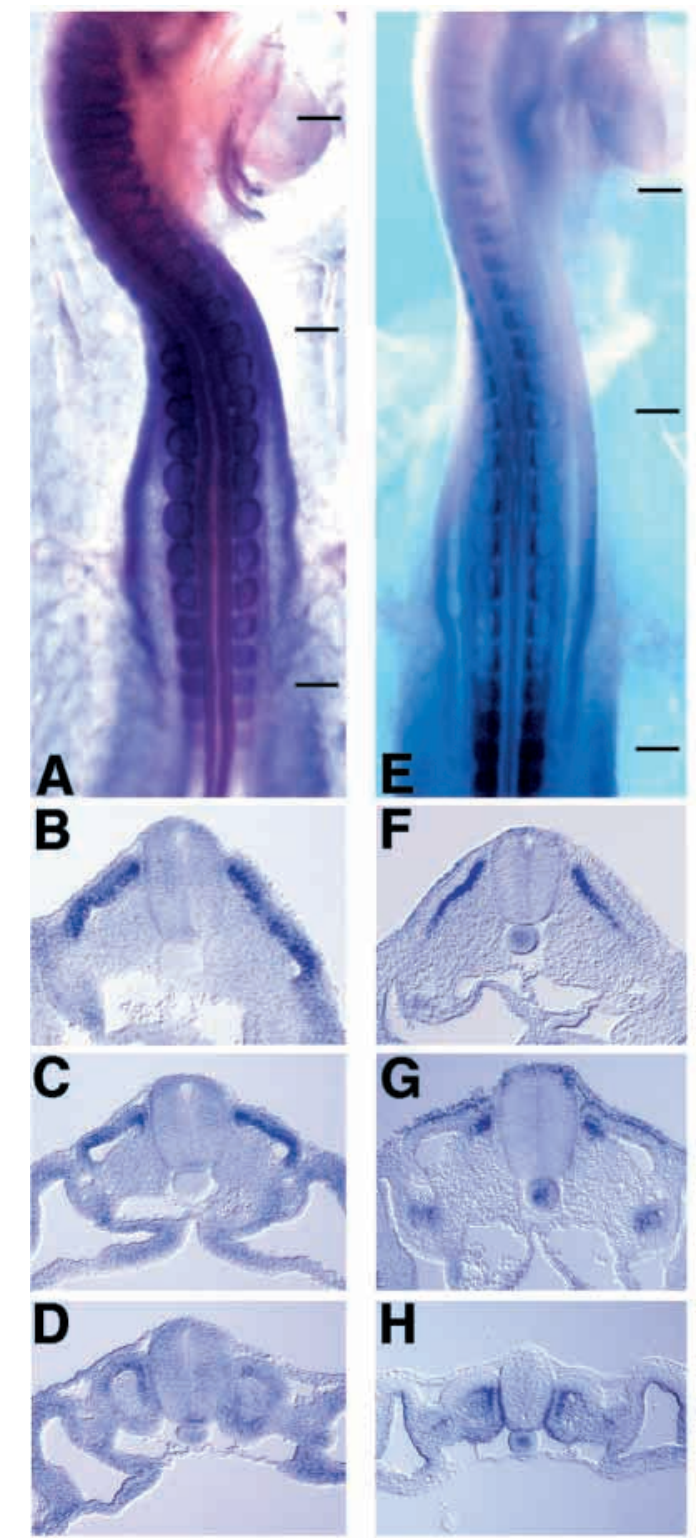

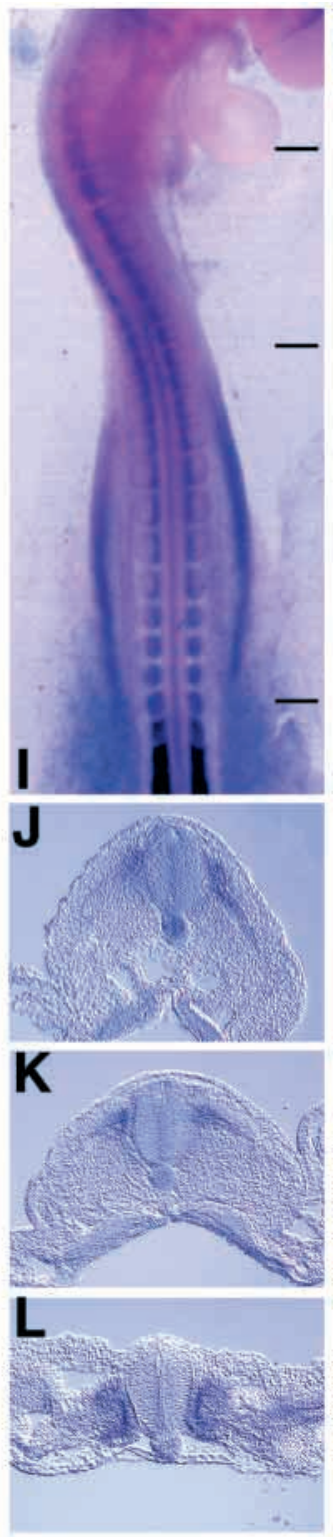


its expression is undetectable in anterior somites of more mature embryos (Fig. 2K) while $M y o D$ is still expressed at high levels (Fig. 2N, HH 22).

\section{Expression of Fz1, $\beta$-catenin and Lef1 in presence of Shh and Wnt1 signals precedes onset of MyoD expression in somite explants}

The timing of expression of $\beta$-catenin and $M y o D$ in paraxial mesoderm in vivo suggests that a $\beta$-catenin dependent Wnt signalling pathway is involved in early steps of myogenic determination. To investigate this possibility further, we monitored expression of $F z 1, \beta$-catenin and Lefl in explants cultured in presence of Shh and Wnt1. At the time of dissection, presegmented mesoderm contains low levels of $F z 1$, intermediate levels of $\beta$-catenin, high levels of Lefl transcripts and no detectable expression of MyoD or $M y h$ (Fig. 3, lane 1). After a 48 hour exposure of this tissue to both Wnt1 and Shh, high levels of $F z 1, \beta$-catenin, Lefl, MyoD and Myh are detected (Fig. 3, lane 4). In the absence of both Shh and Wnt1, expression of $F z 1, \beta$-catenin and Lefl is not maintained in culture (data not shown) and expression of myogenic genes is not activated (Münsterberg et al., 1995). Increased expression of $F z 1$ during the culture period in response to Wnt1 and Shh signals precedes maximal expression of MyoD. $\beta$-catenin expression levels remain fairly constant throughout the culture period. Interestingly, Lefl expression levels decrease upon differentiation of presegmented mesoderm in culture (Fig. 3, lanes 1 and 2), mimicking very closely the expression pattern obtained by in situ hybridisation (Fig. 1I). Lefl expression is,

Fig. 2. Timing of $\beta$-catenin and $M y o D$ expression during somitogenesis. Embryos with the same number of somites were harvested and either hybridised with a probe against $\beta$-catenin (A-D,I-K) or MyoD (E-H,L-N). Whole-mount views of stage $\mathrm{HH}$ 12 embryos are shown in $(\mathrm{A}, \mathrm{E})$ the corresponding sections are shown in (B-D,F-H). The most posterior sections are shown in the bottom panels $(\mathrm{D}, \mathrm{H})$. Wholemount views of stage $\mathrm{HH} 14$ embryos are shown in $(\mathrm{I}, \mathrm{L})$; the corresponding sections are shown in $(\mathrm{J}, \mathrm{M})$. Sections were taken at different axial levels, as indicated by horizontal black lines.

Sections through a somite with a mature myotome derived from a HH 22 embryo are shown in (K, $\mathrm{N})$.
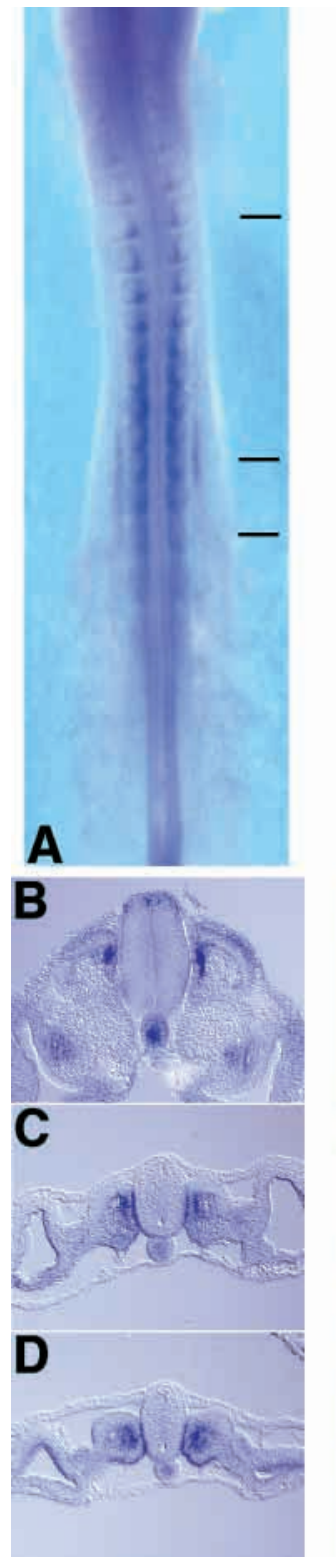

however, maintained and slightly upregulated during the culture period in presence of Shh and Wnt1 signals (Fig. 3, lanes 2-5). In contrast, Lef1 transcripts were not detected in presegmented mesoderm after culture in the presence of either Wnt1 (Fig. 3, lane 6) or Shh (Fig. 3, lane 7) alone. Low levels of $F z 1$ and intermediate levels of $\beta$-catenin were detected in response to either Wnt1 or Shh in the culture (Fig. 3, lanes 6 and 7).

These results show that under conditions that promote activation of myogenic genes (Münsterberg et al., 1995), the components of the Wnt signalling pathway analysed here are expressed before the onset of myogenic gene expression. This strongly supports the idea that this pathway is directly involved in the activation of myogenesis.

\section{A neural tube-derived signal is required for high level $\beta$-catenin expression in medial somites in vivo}

Our expression analysis shows that both $\beta$-catenin and Lefl are expressed in the developing myotome (Fig. 1E-L). However,

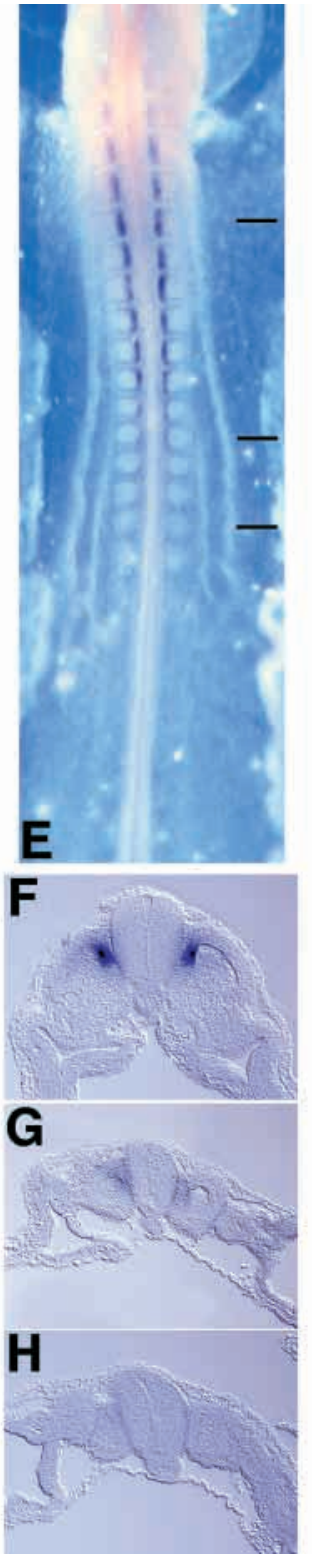

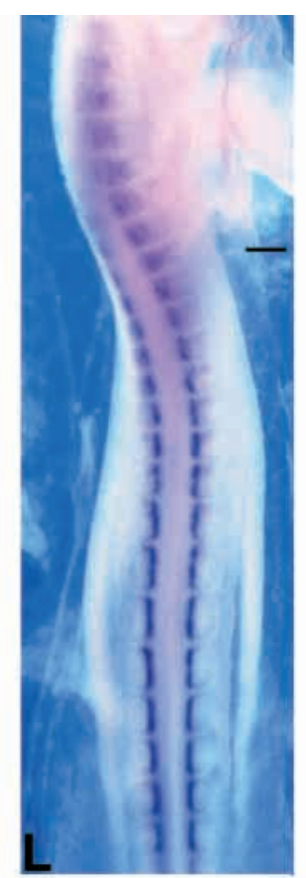

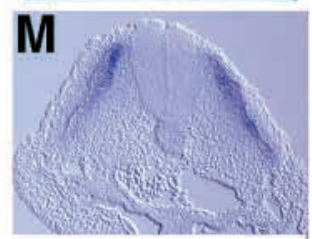

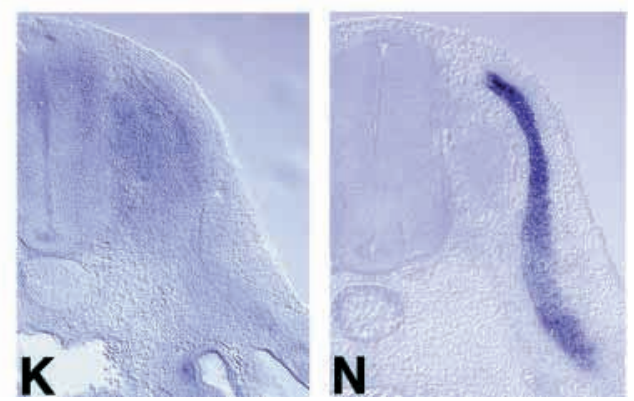




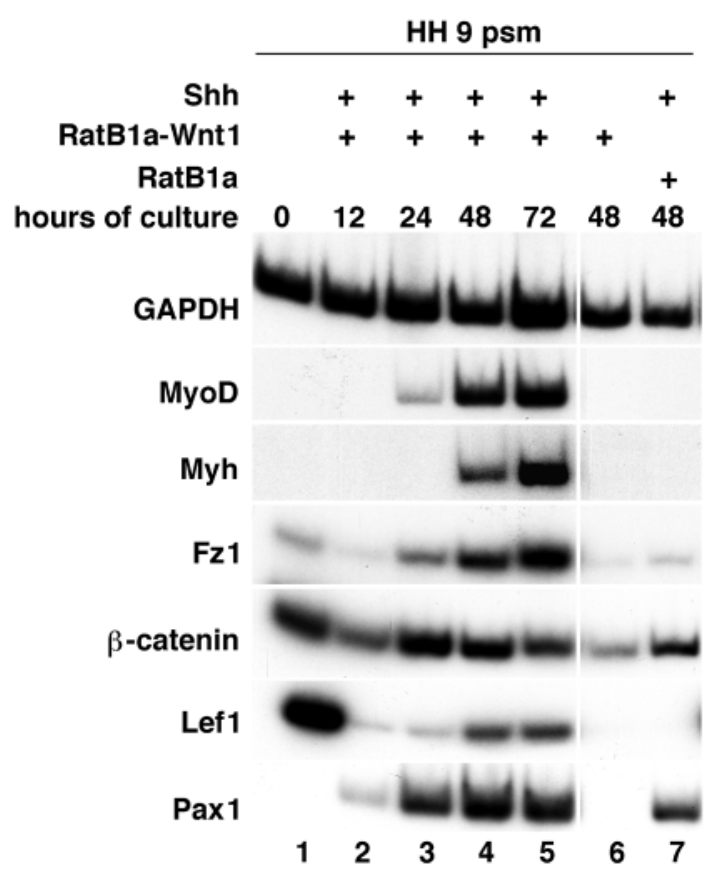

Fig. 3. Timecourse of gene expression in paraxial mesoderm cocultured in the presence of Shh and Wnt1 signals. Presegmented mesoderm (psm) was isolated from HH 9 embryos and cultured in the presence of recombinant Shh and RatB1a fibroblasts expressing Wnt1 (lanes 2-5), in the presence of RatB1a fibroblasts expressing Wnt1 (lane 6) or in the presence of recombinant Shh alone (lane7). RNA was harvested from the explants at the times indicated above each lane (1-7), and analysed for gene expression by RT-PCR. Primer pairs used are indicated on the left of each panel. Paxl expression is shown as a control for active Shh protein. GAPDH, glyceraldehyde-3-phosphate dehydrogenase; Myh, myosin heavy chain. because Lef1 cannot activate transcription in the absence of coactivators, such as $\beta$-catenin, we focussed on the regulation of $\beta$-catenin expression in vivo. In particular, we examined whether $\beta$-catenin expression is under the control of the same signals that govern myogenesis.

The neural tube was surgically removed from HH10 embryos at the level of presegmented mesoderm and replaced by a pellet of RatB1a fibroblasts (Fig. 4B). After 16 to 18 hours, embryos were analysed for $\beta$-catenin expression. Neural tube ablation results in loss of high-level $\beta$-catenin expression in the dorsomedial lip of the myotome (Fig. 4B) compared with normal expression in nonmanipulated embryos (Fig. 4A). Low levels of $\beta$-catenin expression are detected throughout the ventral somite.

We examined whether $\beta$-catenin expression could be rescued by implanting pellets of Wnt-expressing fibroblasts after neural tube ablation (Fig. 4C-F). Implantation of RatB1a fibroblasts expressing either Wnt1 (Fig. 4C) or Wnt3a (Fig. 4E) leads to normal induction of $\beta$-catenin expression. In contrast, pellets of Wnt5a- (Fig. 4D) or Wnt7a-expressing cells (Fig. 4F) cannot rescue $\beta$-catenin expression after neural tube removal.

This experiment demonstrates that Wnt1 or Wnt3a expressing cells can substitute for the presence of the neural tube and induce $\beta$-catenin expression in medial somites in presence of the notochord.

\section{The presence of either notochord or Shh is required for Wnt mediated rescue of $\beta$-catenin expression in the myotome}

We next investigated the role of notochord and Shh for high level $\beta$-catenin expression in vivo. Removal of both neural tube and notochord leads to complete downregulation of $\beta$-catenin expression in adjacent somites (Fig. 5A). This cannot be rescued by implantation of Wnt1- or Wnt3a-expressing cell
Fig. 4. Expression of $\beta$ catenin in the myotome is controlled by a Wnt-mediated signal from the neural tube. In ovo surgical manipulations are schematically indicated on the left of each panel and were performed on $\mathrm{HH}$ stage 10 embryos in the region of presegmented mesoderm. After a further incubation of 16 to 18 hours, embryos were harvested and hybridised with a $\beta$ catenin probe. Sections through the operated regions are shown. The normal expression of $\beta$-catenin in a nonmanipulated embryo is shown in (A). High-level $\beta$ catenin expression is lost after removal of the neural tube (B), a pellet of parental RatB1a fibroblast cells was grafted in place of the neural tube.

Expression of $\beta$-catenin was rescued when a pellet of RatB1a fibroblast cells expressing either Wnt1 (C) or Wnt3a (E) was grafted in place of the neural tube. Expression of $\beta$-catenin was not rescued when a pellet of RatB1a fibroblast cells expressing either Wnt5a (D) or Wnt7a (F) was grafted in place of the neural tube.
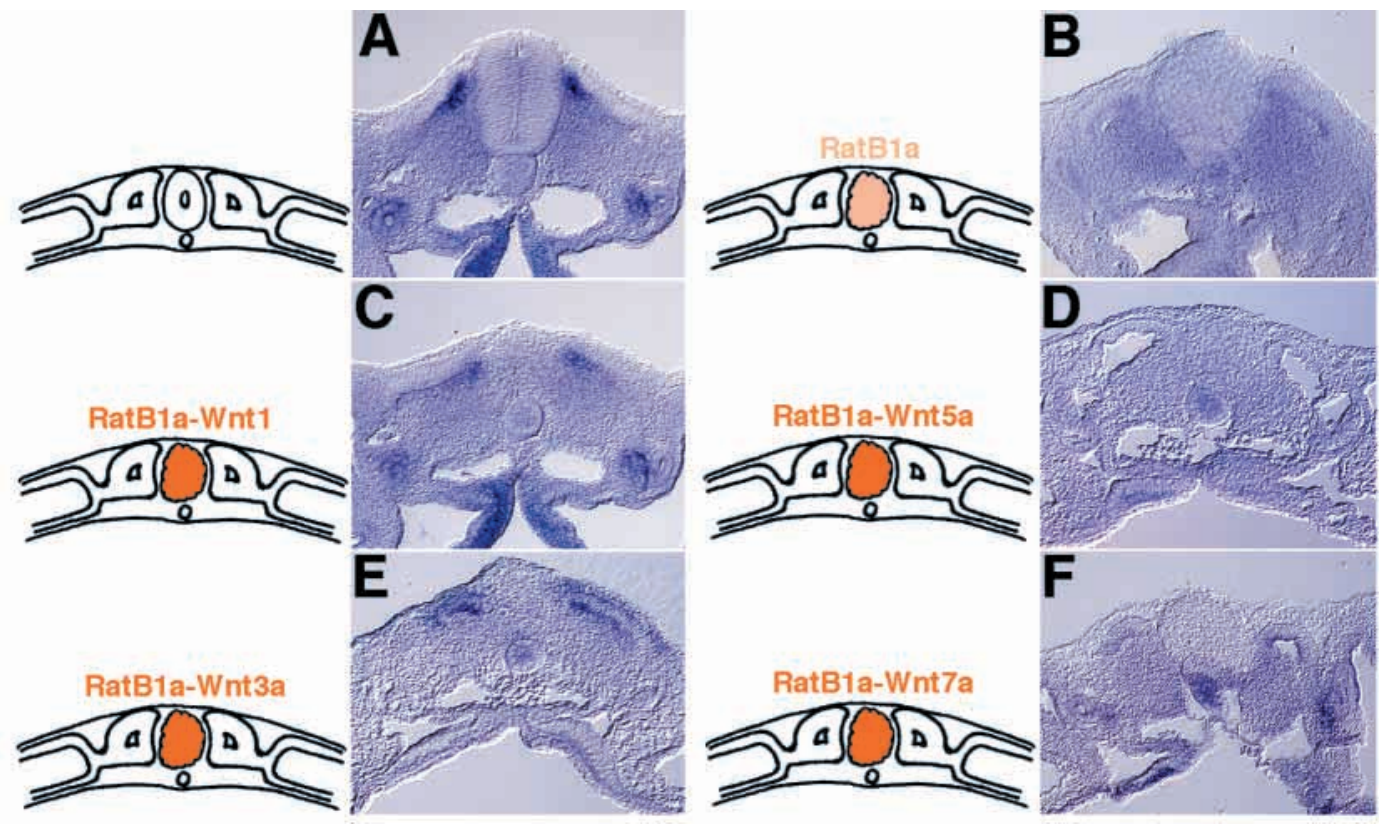

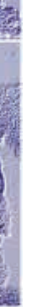




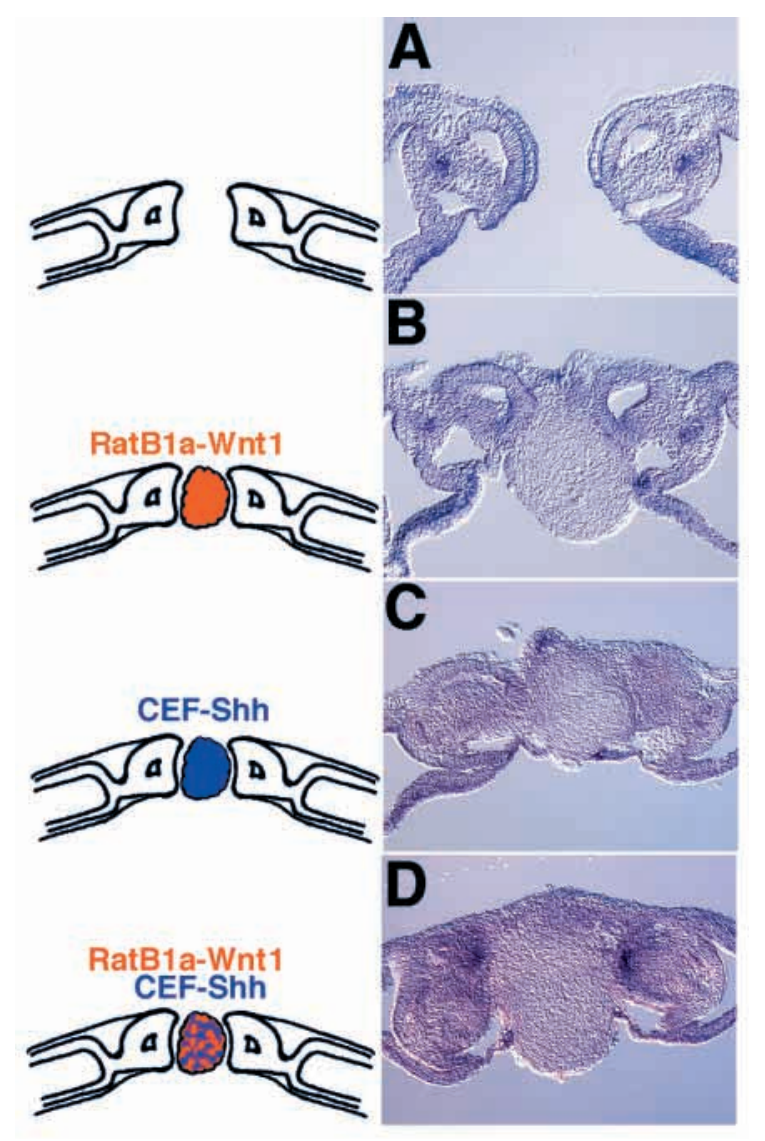

Fig. 5. Notochord-derived signals or Shh are required for Wnt1 (and Wnt3a)-mediated rescue of $\beta$-catenin expression. In ovo surgical manipulations are schematically indicated on the left of each panel and were performed on HH 10 embryos in the region of presegmented mesoderm. After a further incubation of 16 to 18 hours, embryos were harvested and hybridised with a $\beta$-catenin probe. Sections through the operated regions are shown. Removal of both neural tube and underlying notochord results in complete loss of $\beta$-catenin expression in the adjacent somite (A). $\beta$-catenin expression is not rescued by pellets of RatB1a fibroblast cells expressing either Wnt1 (B) or Wnt3a (not shown) grafted in place of neural tube/notochord. The implantation of a cell pellet expressing Shh is not sufficient to induce high levels of $\beta$-catenin expression in the medial somite (C). High-level $\beta$-catenin expression in the medial somite was rescued by implantation of a mixed cell pellet of Shh and Wnt1 (or Wnt3a, not shown) expressing cells (D).

pellets (Fig. 5B and data not shown), indicating that Wnt1 and Wnt3a cooperate with notochord derived signals to induce $\beta$ catenin expression (Fig. 4C,E). Implanting cells that express Shh does not activate high level $\beta$-catenin expression in the myotome (Fig. 5C). However, implantation of a mixed cell pellet, containing both Wnt1- and Shh-expressing cells, results in induction of $\beta$-catenin expression in medial somite regions (Fig. 5D). This suggests that the presence of both, Shh and Wnt 1 or Wnt3a, is required to induce high levels of $\beta$-catenin in the medial somite.

\section{An inhibitory signal from lateral plate mesoderm restricts $\beta$-catenin expression to the medial myotome}

It has been demonstrated that myogenic gene expression is

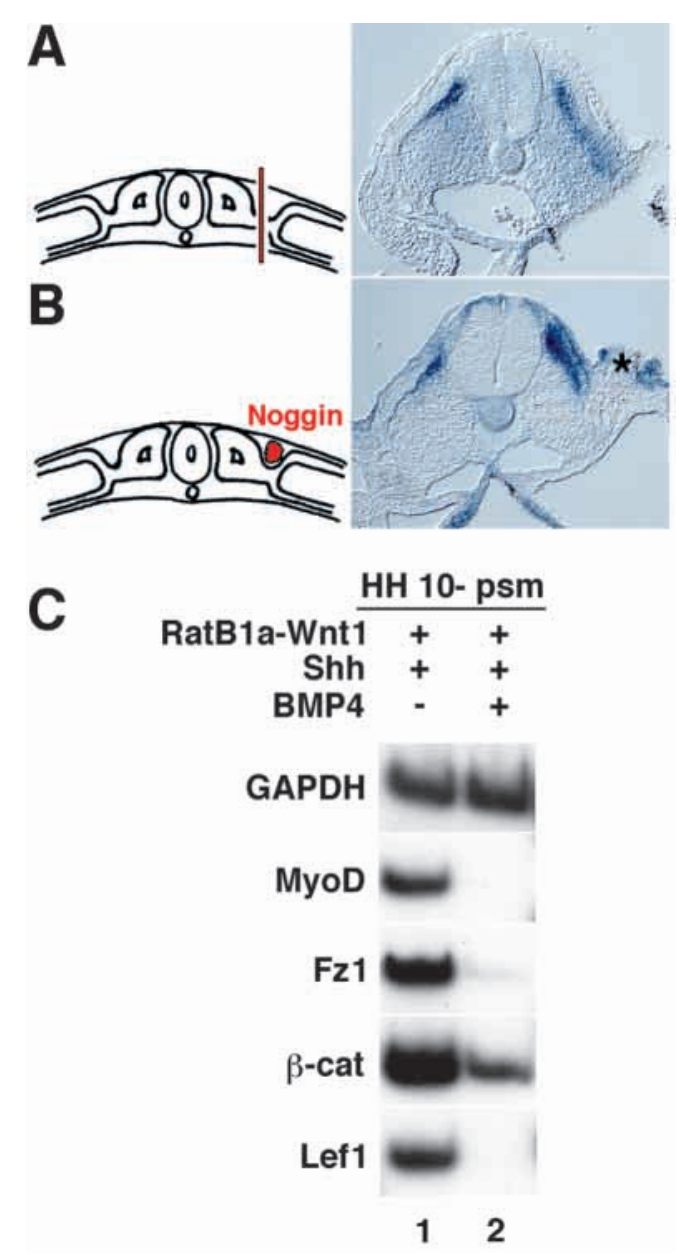

Fig. 6. A Bmp4-mediated signal derived from lateral plate mesoderm restricts $\beta$-catenin expression to medial somites. As before, in ovo surgical manipulations are schematically indicated on the left of each panel and were performed on HH10 embryos in the region of presegmented mesoderm. After a further incubation of 16 to 18 hours, embryos were harvested and hybridised with a $\beta$-catenin probe. Introduction of an impermeable barrier between lateral plate mesoderm and paraxial mesoderm (A) results in expansion of $\beta$ catenin expression to lateral somite regions. Implanting noggin expressing $\mathrm{CHO}$ cells lateral to the somite results in ectopic $\beta$ catenin expression in lateral somite (B), * indicates position of $\mathrm{CHO}$ noggin cells. (C) Bmp4 negatively regulates expression of $M y o D$, $F z 1, \beta$-catenin and Lefl in the presence of Shh and Wnt1 in presegmented mesoderm explants. Presegmented mesoderm (psm) was isolated from HH10 embryos and cultured in the presence of RatB1a fibroblasts expressing Wnt1 and recombinant Shh (lanes 1,2) in the absence (lane 1) or presence (lane 2) of Bmp4 in the culture medium. RNA was harvested from the explants after 2.5 days and analysed for gene expression by RT-PCR. Primer pairs used are indicated on the left of each panel. The high levels of MyoD, Fz1, $\beta$-catenin and Lef1 expression observed in response to Shh and Wnt1 (C, lane 1) are either completely abolished $(M y o D, L e f 1)$ or significantly reduced ( $F z 1, \beta$-catenin) by Bmp4 (C, lane 2).

restricted to medial somite regions, owing to the action of Bmp4, which is derived from lateral plate mesoderm. We investigated whether $\beta$-catenin expression is restricted by the same mechanism.

We introduced an impermeable barrier between somite and 
lateral plate mesoderm (Fig. 6A). This manipulation leads to the expansion of $\beta$-catenin expression to more-lateral somite regions. This suggests that an inhibitory signal from lateral plate mesoderm normally inhibits $\beta$-catenin expression laterally, thereby restricting it to medial somite regions. To test whether this inhibition is mediated by Bmp4 we grafted a pellet of noggin-expressing cells lateral to the somite. This manipulation results in ectopic $\beta$-catenin expression (Fig. 6B), compared with somites on the contralateral side.

Thus, antagonising Bmp4 activity by noggin is sufficient to induce ectopic $\beta$-catenin expression.

\section{Myogenesis and expression of Wnt pathway components are inhibited by Bmp4 in vitro}

Activation of myogenic gene expression in response to Wnt1 and Shh can be inhibited by Bmp4 (Reshef et al., 1998). We analysed whether high level expression of the Wnt signalling pathway in presence of Wnt1 and Shh (Fig. 3) can similarly be repressed by Bmp4. We found that explants of presegmented mesoderm express high levels of MyoD, Fz1, $\beta$-catenin and Lefl when cultured with Wnt1 and Shh (Fig. 6C, lane 1). As shown before, activation of skeletal muscle-specific gene expression in somite explants by Wnt 1 and Shh is inhibited by adding Bmp4 to the culture medium (Fig. 6C, lane 2; Reshef et al., 1998). This correlates with the complete inhibition of Lefl expression in the presence of Bmp4 in the culture medium. In addition, $F z 1$ and $\beta$-catenin transcripts, while still detectable, are significantly downregulated in this situation (Fig. 6C, lane 2).

\section{DISCUSSION}

Experiments in both chick and mouse embryos have demonstrated that Shh, Wnt family members, Bmp4 and noggin play a role for establishing the early myotome at the correct position (Borycki et al., 1998; Hirsinger et al., 1997; Johnson et al., 1994; Marcelle et al., 1997; Münsterberg et al., 1995; Pourquié et al., 1996; Reshef et al., 1998; Stern et al., 1995, 1997), the dorsomedial lip of the somite (Denetclaw et al., 1997) adjacent to the neural tube.

In this paper we investigated the mechanism by which the Wnt-mediated signal is relayed to myogenic precursors. The data presented are consistent with the idea that the Wnt signal acts through a $\beta$-catenin-dependent pathway. Furthermore, Wnt and Shh are involved in regulating expression of Wnt pathway components, such as $\beta$-catenin.

\section{$\beta$-catenin and Lef1 play a role in the specification of the early myotome}

Our expression analysis revealed that a number of genes, known to act downstream of Wnt, i.e., Fzl, $\beta$-catenin and Lef1, are expressed in a dynamic pattern during somitogenesis (Fig. 1). $\beta$-catenin and Lef1 have been shown to interact to activate transcription (Behrens et al., 1996; Molenaar et al., 1996). They show a striking overlap in expression in differentiating somites (Fig. 1), suggesting that they interact and relay the Wnt signal within early myotomal cells. However, we cannot exclude that other Lef/TCF family members interact with $\beta$ catenin in this context. Lef/TCF family members cannot activate transcription on their own (Molenaar et al., 1996), and in the absence of co-activators, such as $\beta$-catenin, they function as transcriptional respressors (Cavallo et al., 1998; Roose et al., 1998). We speculate that expression of $\beta$-catenin during somitogenesis is the rate-limiting step that determines Lef/TCF transcriptional activity. In addition, it is possible that increased levels of $\beta$-catenin expression reflect changes in cell adhesion during myotome formation.

It has been shown previously that levels of $\beta$-catenin protein are post-transcriptionally regulated by phosphorylation and protein turnover (Aberle et al., 1997), and accumulation of protein has been observed at somite boundaries in Xenopus embryos (Fagotto and Gumbiner, 1994). The accumulation of transcripts in the developing myotome suggests that $\beta$-catenin is also regulated at the level of transcription.

We found that $\beta$-catenin and Lef1 transcripts became restricted to the medial somite (Fig. 1E,I) and high levels could first be seen in the dorsomedial lip of the myotome as it forms during somitogenesis (Fig. 1G,K). Because we found that high level $\beta$-catenin and Lefl expression in the somite was specific to myotomal cells, it is tempting to speculate that already in epithelial somites $\beta$-catenin and Lef1 may identify early myogenic precursors (Figs 1H,L, 2D).

The comparative analysis of $\beta$-catenin and MyoD expression shows that both genes are expressed in the same domain of differentiating somites (Fig. 2A-J,L,M). In addition, we found that $\beta$-catenin is expressed and medially restricted before any $M y o D$ transcripts can be detected (compare Fig. 2D and $\mathrm{H}$ ). In our hands, $M y o D$ is the first myogenic bHLH transcription factor that can be detected in specified myoblasts by in situ hybridisation. However, Myf5 transcripts are detectable by RTPCR in presegmented mesoderm. In this tissue, cells are not yet committed to a myogenic fate. Consistent with this, Myf5 expression is still dependent on the presence of myogenic inducers, Wnt1 and Shh (Maroto et al., 1997). The analysis of knockout mice and work in chick embryos has suggested two parallel pathways that can result in myogenesis (Maroto et al., 1997; Rawls and Olson, 1997; Tajbakhsh et al., 1997). One pathway is proposed to act via Pax3 and MyoD while the second pathway is proposed to act via Myf5 in a manner independent of Pax3. Together, these findings are consistent with the idea that $\beta$-catenin acts upstream of the myogenic determination gene, $M y o D$, is involved in specification of myotomal cells and may predominantly control release of myoblasts from the dermomyotomal lip.

Functional experiments in chick embryos have previously addressed the role of Wnt and $\beta$-catenin signalling in dorsoventral somite patterning (Capdevila et al., 1998). Capdevila and colleagues investigated effects of RCAS retrovirus-mediated overexpression of Wnt 1 or an activated form of $\beta$-catenin, following injection into $\mathrm{HH} 10$ pre-segmented mesoderm. This treatment resulted in abrogated expression of the sclerotomal gene, Paxl, in ventral somite regions and expansion of dermomyotomal gene expression to more lateral somite domains 48 hours later. However, surprisingly no effect on myogenic gene expression was observed. Our results strongly suggest that $\beta$-catenin does function as an effector of Wnt signalling in the epiaxial myotome of the somite. It is possible that in the RCAS-mediated overexpression experiments (Capdevila et al., 1998), negatively acting factors could not be overcome by providing excess Wnt1 and/or $\beta$-catenin. Furthermore, additional positive factors may be required, as we show that Lefl expression is highly restricted to the myotome. 
Alternatively, somitic precursors may have been irreversibly specified at the time that RCAS-mediated overexpression of Wnt $1 / \beta$-catenin is manifested.

\section{Components of the Wnt pathway are upregulated prior to activation of skeletal muscle specific gene expression in response to myogenic signals, Shh and Wnt1, in vitro}

RT-PCR demonstrated that $F z 1, \beta$-catenin and Lefl transcripts are expressed in presegmented mesoderm (Fig. 3, lane 1). However, this expression was not stable and was not maintained when presegmented mesoderm was cultured on its own, in the absence of axial midline tissues (data not shown), suggesting that positive signals are necessary for maintenance and upregulation of $F z 1, \beta$-catenin and Lefl expression at this stage. We show here that Shh and Wnt1-mediated signalling plays a role in this process. We show that Shh and Wnt1/Wnt3a, which are expressed in axial tissues, floor plate/notochord and neural tube respectively, are involved in regulating expression of $\beta$-catenin in vivo. As shown before, we found that skeletal muscle-specific gene expression is activated in somite explants in the presence of both Shh and Wnt (Münsterberg et al., 1995) (Fig. 3). Skeletal muscle differentiation as manifested by expression of $M y o D$ and $M y h$, correlated with high levels of Fzl, $\beta$-catenin and Lefl expression in response to Shh and Wnt1 after 48 hours (Fig. 3, lane 4). The timecourse of $F z 1, \beta$-catenin and Lefl expression showed that these genes are expressed in explants of presegmented mesoderm, before myogenic genes are induced (Fig. 3, lane 1). Furthermore, their expression increased in response to a combination of Shh and Wnt1 signals prior to $(\beta$ catenin), or concomitant with $(F z 1$, Lefl) the increased expression of $M y o D$ and the onset of $M y h$ gene expression.

It is interesting to note that, in mouse, expression of $F z l$ is more highly restricted to the medial edge of newly formed somites (Borello et al., 1999) in a pattern similar to that observed for $\beta$-catenin and Lefl. While we cannot exclude the possibility that other Wnt receptors and/or Lef/TCF family members are involved, the timing of $F z 1, \beta$-catenin, Lefl, and $M y o D$ and $M y h$ expression in explants (Fig. 3), and the timing of $\beta$-catenin and $M y o D$ expression in vivo (Fig. 2) supports the idea that Wnt1 may act through Fz1, $\beta$-catenin and Lef1 to activate myogenesis. Our results suggest that there is a functional difference between the induction of epaxial and hypaxial muscle precursors, as $\beta$-catenin and Lefl are only expressed in the epaxial myotome.

\section{$\beta$-catenin expression is controlled by myogenic signals in vivo}

In this study we examined how signalling molecules, derived from tissues surrounding the somite, influence $\beta$-catenin expression in vivo. Surgical manipulations in chick embryos have demonstrated that Wnt1, Shh, Bmp4 and noggin act together to regulate expression of $M y o D$, and to restrict its expression to medial somite regions. We show here that $\beta$ catenin expression in the somite is governed by the same signals (Figs 4-6). In the absence of the neural tube, low levels of $\beta$-catenin expression were detected in the ventral mesenchymal part of the somite, most likely due to the presence of the notochord (Fig. 4B). However, high-level $\beta$ catenin expression in the dorsomedial lip of the myotome was abolished after neural tube ablation (Fig. 4B). Thus, a positive signal from the neural tube is necessary for both upregulation of $\beta$-catenin expression and activation of $M y o D$ expression in the epaxial myotome.

The surface ectoderm has also been shown to activate skeletal muscle differentiation in somite explants (Reshef et al., 1998) and this may be mediated by Wnt4 and Wnt6 (Fan et al., 1997). Interestingly, the surface ectoderm was not sufficient to induce $\beta$-catenin expression in the dorsomedial lip of the myotome (Fig. 4B), suggesting that the myogenic signal derived from surface ectoderm may not act through $\beta$-catenin. We cannot exclude the possibility that surface ectoderm derived factor(s) may play a role for the expression of Lef1 and particularly $F z l$, which is expressed throughout the dermomyotome.

We found that Wnt1 and Wnt3a can activate $\beta$-catenin expression in vivo. Wnt5a and Wnt7a, which do not activate myogenic gene expression (Münsterberg et al., 1995; and A. M., unpublished data) and have been shown to act in a $\beta$ catenin independent fashion (Kengaku et al., 1998), are not able to rescue $\beta$-catenin expression after neural tube removal (Fig. 4D,F). High-level $\beta$-catenin expression in the dorsomedial somite requires the presence of either the notochord (Fig. 4C,E) or Shh (Fig. 5D). Only low levels of $\beta$ catenin transcripts were detected throughout the somite in response to either Wnt1- or Shh-expressing cells in vivo (Fig. $5 \mathrm{~B}, \mathrm{C})$. In contrast, the relative levels of $\beta$-catenin transcripts were surprisingly high in somite explants cultured in the presence of either Wnt1 or Shh alone (Fig. 3, lanes 6, 7). Even though it is difficult to compare in situ hybridisation with RTPCR, this apparent difference may indicate the absence of an inhibitory factor, such as Bmp4, in vitro.

\section{Expression of Wnt pathway components and 'myogenic competence'}

Taken together, our data suggest that $\beta$-catenin and Lef1 are involved in establishing the early myotome. We propose that expression of Wnt pathway components in pre-segmented mesoderm plays an important role in terms of the 'competence' of this tissue to myogenic induction. The activation of this pathway, perhaps initially by Shh-mediated signalling, would render precursor cells responsive to Wnts. We have shown
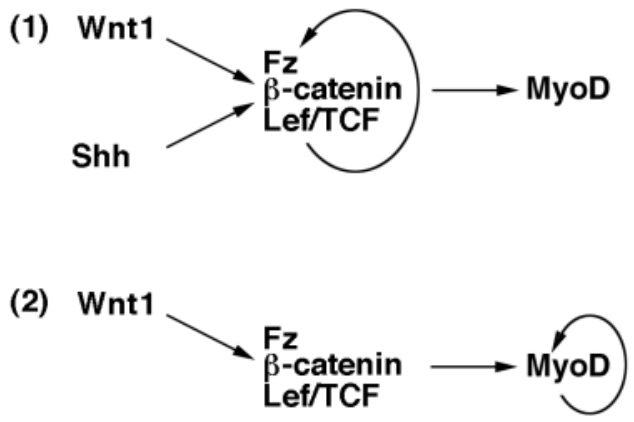

Fig. 7. Proposed model of events that lead to stable induction of myogenesis in the somite. (A) Wnt and Shh act together to induce high levels of Wnt pathway components. This results in the activation of skeletal muscle genes. (B) The Wnt pathway is stably induced and Shh is no longer required. Ultimately skeletal muscle differentiation becomes autonomous. 
previously that Shh is transiently required for myogenic differentiation in vitro, and show in this paper that both Shh and Wnt1 contribute to the regulation of $F z 1, \beta$-catenin and Lefl expression. These results indicate that a positive feedback loop is involved in establishing high-level expression of the Wnt pathway in myogenic precursors. The pathway is still expressed in the newly formed myotome, indicating that it may also be important for maintenance of myogenic commitment and early differentiation. We speculate that once the Wnt pathway is stably induced, its expression becomes independent of Shh. Finally, skeletal muscle differentiation becomes independent of cues from axial tissues and at this stage the Wnt signalling pathway may be downregulated in the somite (Fig. 7 ). Consistent with this model, high-level $\beta$-catenin expression in the myotome is lost in mature somites (Fig. 2K).

We thank C. Tickle, S. Hoppler and G. Wheeler for critical comments on the manuscript; O. Pourquié for valuable advice; R. Harland for the noggin-expressing cells; J. Kitajewski for the Wntexpressing cells; Ontogeny (Cambridge, MA) for the Shh protein; B. Patterson for the chicken $M y o D$ cDNA; E. Farrell, the Tickle and the Hoppler laboratories for stimulating discussions; and our anonymous reviewers for their insightful comments. M. S. is funded by the Catherine Cookson Prize Studentship, A. M. and work is the laboratory are funded by the Wellcome Trust Research Career Development Award.

\section{REFERENCES}

Aberle, H., Bauer, A., Stappert, J., Kispert, A. and Kemler, R. (1997). $\beta$ catenin is a target for the ubiquitin-proteasome pathway. FASEB J. 11, 32323232.

Arias, A. M., Brown, A. M. C. and Brennan, K. (1999). Wnt signalling: pathway or network? Curr. Opin. Genet. Dev. 9, 447-454.

Behrens, J., Vonkries, J. P., Kuhl, M., Bruhn, L., Wedlich, D., Grosschedl, R. and Birchmeier, W. (1996). Functional interaction of $\beta$-catenin with the transcription factor Lef-1. Nature 382, 638-642.

Borello, U., Coletta, M., Tajbakhsh, S., Leyns, L., De Robertis, E. M., Buckingham, M. and Cossu, G. (1999). Transplacental delivery of the Wnt antagonist Frzb1 inhibits development of caudal paraxial mesoderm and skeletal myogenesis in mouse embryos. Development 126, 4247-4255.

Borycki, A. G., Mendham, L. and Emerson, C. P. (1998). Control of somite patterning by Sonic hedgehog and its downstream signal response genes. Development 125, 777-790.

Buffinger, N. and Stockdale, F. E. (1994). Myogenic specification in somites - induction by axial structures. Development 120, 1443-1452.

Capdevila, J., Tabin, C. and Johnson, R. L. (1998). Control of dorsoventral somite patterning by Wnt-1 and $\beta$-catenin. Dev.l Biol. 193, 182-194.

Cavallo, R. A., Cox, R. T., Moline, M. M., Roose, J., Polevoy, G. A., Clevers, H., Peifer, M. and Bejsovec, A. (1998). Drosophila Tcf and Groucho interact to repress Wingless signalling activity. Nature 395, 604-608.

Christ, B. and Ordahl, C. P. (1995). Early stages of chick somite development. Anat. Embryol. 191, 381-396.

Denetclaw, W. F., Christ, B. and Ordahl, C. P. (1997). Location and growth of epaxial myotome precursor cells. Development 124, 1601-1610.

Fagotto, F. and Gumbiner, B. M. (1994). $\beta$-catenin localization during Xenopus embryogenesis - accumulation at tissue and somite boundaries. Development 120, 3667-3679.

Fan, C. M., Lee, C. S. and Tessier-Lavigne, M. (1997). A role for WNT proteins in induction of dermomyotome. Dev. Biol. 191, 160-165.

Henrique, D., Adam, J., Myat, A., Chitnis, A., Lewis, J. and Ishhorowicz, D. (1995). Expression of a delta-homolog in prospective neurons in the chick. Nature 375, 787-790.

Hirsinger, E., Duprez, D., Jouve, C., Malapert, P., Cooke, J. and Pourquié, O. (1997). Noggin acts downstream of Wnt and Sonic Hedgehog to antagonize BMP4 in avian somite patterning. Development 124, 4605-4614.

Johnson, R. L., Laufer, E., Riddle, R. D. and Tabin, C. (1994). Ectopic expression of Sonic hedgehog alters dorsal-ventral patterning of somites. Cell 79, 1165-1173.

Kengaku, M., Capdevila, J., Rodriguez-Esteban, C., De La Peña, J., Johnson, R. L., Belmonte, J. C. I. and Tabin, C. J. (1998). Distinct WNT pathways regulating AER formation and dorsoventral polarity in the chick limb bud. Science 280, 1274-1277.

Kengaku, M., Twombly, V. and Tabin, C. (1997). Expression of Wnt and Frizzled genes during chick limb bud development. Cold Spring Harbor Symp. Quant. Biol. 62, 421-429.

Lamb, T. M., Knecht, A. K., Smith, W. C., Stachel, S. E., Economides, A. N., Stahl, N., Yancopolous, G. D. and Harland, R. M. (1993). Neural Induction by the secreted polypeptide noggin. Science 262, 713-718.

Lu, J. F., Chuong, C. M. and Widelitz, R. B. (1997). Isolation and characterization of chicken $\beta$-catenin. Gene 196, 201-207.

Marcelle, C., Stark, M. R. and BronnerFraser, M. (1997). Coordinate actions of BMPs, Wnts, Shh and noggin mediate patterning of the dorsal somite. Development 124, 3955-3963.

Maroto, M., Reshef, R., Münsterberg, A. E., Koester, S., Goulding, M., Lassar, A. B. (1997). Ectopic Pax-3 activates MyoD and Myf-5 expression inembryonic mesoderm and neural tissue. Cell 89, 139-148.

Molenaar, M., Vandewetering, M., Oosterwegel, M., Petersonmaduro, J., Godsave, S., Korinek, V., Roose, J., Destree, O. and Clevers, H. (1996). Xtcf-3 transcription factor mediates $\beta$-catenin-induced axis formation in Xenopus embryos. Cell 86, 391-399.

Moon, R. T., Brown, J. D. and Torres, M. (1997). WNTs modulate cell fate and behavior during vertebrate development. Trends Genet. 13, 157-162.

Münsterberg, A. E., Kitajewski, J., Bumcrot, D. A., McMahon, A. P. and Lassar, A. B. (1995). Combinatorial signaling by Sonic hedgehog and Wnt family members induces myogenic bHLH gene expression in the somite. Genes Dev. 9, 2911-2922.

Münsterberg, A. E. and Lassar, A. B. (1995). Combinatorial signals from the neural tube, floor plate and notochord induce myogenic bHLH gene expression in the somite. Development 121, 651-660.

Pourquié, O., Coltey, M., Breant, C. and Le Douarin, N. M. (1995). Control of somite patterning by signals from the lateral plate. Proc. Natl. Acad. Sci. USA 92, 3219-3223.

Pourquié, O., Fan, C. M., Coltey, M., Hirsinger, E., Watanabe, Y., Bréant, C., Francis-West, P., Brickell, P., Tessier-Lavigne, M. and Le Douarin, N. M. (1996). Lateral and axial signals involved in avian somite patterning: a role for BMP4. Cell 84, 461-471.

Pownall, M. E., Strunk, K. E. and Emerson, C. P. (1996). Notochord signals control the transcriptional cascade of myogenic bHLH genes in somites of quail embryos. Development 122, 1475-1488.

Rawls, A. and Olson, E. N. (1997). MyoD meets its maker. Cell 89, 5-8.

Reshef, R., Maroto, M. and Lassar, A. B. (1998). Regulation of dorsal somitic cell fates: BMPs and noggin control the timing and pattern of myogenic regulator expression. Genes Dev. 12, 290-303.

Roose, J., Molenaar, M., Peterson, J., Hurenkamp, J., Brantjes, H., Moerer, P., vandeWetering, M., Destree, O. and Clevers, H. (1998). The Xenopus Wnt effector XTcf-3 interacts with Groucho-related transcriptional repressors. Nature 395, 608-612.

Stern, C. D. (1993) Immunocytochemistry of embryonic material. In: Essential Developmental Biology - A Practical Approach (ed. C. D. Stern and P. W. H. Holland), pp. 193-212. Oxford: Oxford University Press

Stern, H. M., Brown, A. M. and Hauschka, S. D. (1995). Myogenesis in paraxial mesoderm: preferential induction by dorsal neural tube and by cells expressing Wnt-1. Development 121, 3675-3686.

Stern, H. M. and Hauschka, S. D. (1995). Neural tube and notochord promote in vitro myogenesis in single somite explants. Dev. Biol. 167, 87-103.

Stern, H. M., Lin-Jones, J. and Hauschka, S. D. (1997). Synergistic interactions between bFGF and a TGF-beta family member may mediate myogenic signals from the neural tube. Development 124, 3511-3523.

Tajbakhsh, S., Rocancourt, D., Cossu, G. and Buckingham, M. (1997). Redefining the genetic hierarchies controlling skeletal myogenesis: Pax-3 and Myf-5 act upstream of MyoD. Cell 89, 127-138.

Tajbakhsh, S., Borello, U., Vivarelli, E., Kelly, R., Papkoff, J., Duprez, D., Buckingham, M. and Cossu, G. (1998). Differential activation of Myf5 and MyoD by different Wnts in explants of mouse paraxial mesoderm and the later activation of myogenesis in the absence of Myf5. Development 125, 4155-4162.

Tajbakhsh, S. and Cossu, G. (1997). Establishing myogenic identity during somitogenesis. Curr. Opin. Genet. Dev. 7, 634-641.

Willert, K. and Nusse, R. (1998). $\beta$-catenin: a key mediator of Wnt signaling. Curr. Opin. Genet. Dev. 8, 95-102. 